\title{
A DESCRIMINALIZAÇÃO DO ABORTO E O ATIVISMO JUDICIAL: A PROTEÇÃO DOS DIREITOS FUNDAMENTAIS DA MULHER
}

\section{Andressa Tanferri Sentone*}

\section{RESUMO}

Objetiva-se com o presente estudo demonstrar como o Judiciário vem atuando para tentar suprir o silêncio legislativo frente às demandas sociais que evoluem rapidamente e acabam se distanciando das normas penais vigentes. Nesse sentido, o aborto se enquadra como um dos crimes onde verifica-se o descompasso entre a lei e a realidade social. Para tanto, o trabalho discorrerá sobre o fenômeno do ativismo judicial, destacando a atuação da Corte Constitucional frente à inércia legislativa em debater a questão, bem como analisará as decisões recentes do STF sobre o tema e a proteção dos direitos fundamentais da mulher.

Palavras-chave: Aborto. Descriminalização. Inércia legislativa. Ativismo judicial. Direitos fundamentais.

\section{THE ABORTION'S DISCRIMINATION AND JUDICIAL ACTIVISM: THE WOMEN'S FUNDAMENTAL RIGHTS PROTECTION}

\begin{abstract}
The objective of this study is to demonstrate how the Judiciary has been working to overcome legislative silence in front of the evolving social demands witch are distancing themselves from existing criminal norms. In this sense, abortion is one of the crimes in mismatch between the law and social reality. Therefore, the paper will discuss the phenomenon of judicial activism, highlighting the Constitutional Court's action against the legislative inertia in debating the issue, as well as analyze the recent STF decisions on the subject and the protection of women's fundamental rights.
\end{abstract}

Keywords: Abortion. Decriminalization. Legislative blindspot. Judicial activism. Fundamental rights.

\section{INTRODUÇÃO}

A evolução na proteção dos direitos fundamentais do ser humano, em uma ótica universalista, expandiu o caráter fragmentário do século XVIII, no qual apenas as liberdades individuais eram permeadas de proteção estatal, para reconhecer o ser humano como sujeito de direitos nas suas mais variadas acepções. Porém, a velocidade das circunstâncias sociais acaba distanciando as leis da realidade dos conflitos.

\footnotetext{
* Mestranda em Ciência Jurídica pela UENP, especialista em Direito e Processo Penal (UEL). Docente do Curso de Graduação em Direito da Universidade Pitágoras-Unopar, Londrina/PR. Advogada, andressatanferri@gmail.com
} 
Ao Legislativo, poder eleito, cuja função típica consiste na criação de leis para regular o Estado e a própria sociedade, caberia, pois, disciplinar as demandas sociais com leis necessárias a esta dinâmica. Porém, quando esse papel não é exercido, a sociedade fica diante de uma barreira ao desenvolvimento e progresso de leis adequadas ao tempo presente, chamada de ponto cego legislativo.

Diante da inércia do Legislativo, que se abstém de solucionar conflitos dramáticos envolvendo direitos fundamentais em regra por razões políticas, resta ao Judiciário abraçar uma postura mais proativa na interpretação das normas existentes, a fim de adequá-las às necessidades jurídicas, políticas, culturais e sociais do presente e de compatibilizá-las com a Constituição.

O aborto é considerado um desses conflitos, um problema de saúde pública, polêmico, que envolve embates morais, jurídicos e políticos, e cuja regulamentação remonta ao ano de 1940 quando entrou em vigor o Código Penal ainda vigente. Nessa perspectiva, constantemente o assunto vem sendo objeto de demandas judiciais que chegam até o Supremo Tribunal Federal na busca do preenchimento de suas lacunas e omissões legislativas.

A ideia deste estudo é apresentar de que forma a interpretação criativa da Corte Constitucional vem sendo utilizada para modificar, complementar e até mesmo corrigir a aplicação da lei penal em situações específicas do crime de aborto, fazendo o uso de princípios e da ponderação de direitos para concretizar os preceitos constitucionais.

Para tanto, o presente trabalho irá abordar no primeiro momento o tratamento conferido pela legislação brasileira ao aborto, os tipos penais incriminadores, bem como as causas excludentes da ilicitude já regulamentadas por lei. Em seguida, discorrerá sobre a atuação da Corte Constitucional brasileira frente ao silêncio legislativo, a postura adotada na tomada de decisões, a mudança de paradigma na corte, o desprendimento da interpretação literal das normas e a adoção de uma posição concretista e contramajoritária na defesa dos direitos fundamentais.

Por fim, serão abordadas as decisões históricas do Supremo Tribunal Federal referentes às mudanças de entendimento sobre a criminalização do aborto, agindo como protagonista institucional no processo de transformação social trazendo os principais argumentos e efeitos gerados no mundo jurídico. 
O objetivo principal do presente estudo, consiste, pois, em fazer uma análise das decisões da Corte Constitucional na tentativa de aproximar a justiça da realidade social e método escolhido para desenvolver esta análise, de caráter eminentemente teórico, foi o dedutivo, com revisão bibliográfica e documental, partindo de premissas gerais e verdadeiras relacionadas à ausência de posicionamento do legislativo e objetivando chegar a uma conclusão específica a respeito da mencionada postura proativa do Supremo Tribunal Federal nas decisões relativas ao aborto.

\section{O ABORTO NO ORDENAMENTO JURÍDICO BRASILEIRO ATUAL E AS CAUSAS EXCLUDENTES DE ILICITUDE}

A modulação do crime do aborto está associada ao momento a partir do qual compreende-se que a proteção à vida se tornaria indispensável e isso irá depender da conceituação jurídica adotada pela legislação de cada país. Isso significa dizer que não necessariamente o feto precisará ser considerado uma pessoa humana dotada de personalidade para ser merecedor de proteção estatal.

Para aferir este marco inicial da necessidade de proteção jurídica numerosas teorias buscam justificar, a partir de critérios fisiológicos, o tempo exato em que o nascituro passa a ser ao menos sujeito de direitos e, consequentemente, detentor do direito à vida e à dignidade da pessoa humana.

Dentre as teorias que se debruçam sobre o tema, de natureza civilistas, cumpre trazer à baila a ideia preconizada pela Teoria Concepcionista, segundo a qual somente haverá vida a partir da fecundação óvulo-espermatozoide, que dá origem ao zigoto. Para esta teoria a personalidade civil do nascituro surge desde os primeiros estágios gestacionais, momento em que ainda não é possível determinar se a vida em desenvolvimento biológico será viável ou apresentará alguma anomalia que lhe retire a capacidade de sobrevivência extrauterina, ou que venha a lhe causar a interrupção da vida ainda em ambiente intrauterino.

Há que se ressaltar, também, a Teoria da Personalidade Condicional, segundo a qual a personalidade civil do feto também se inicia desde a concepção, condicionada ao nascimento com vida. Para os adeptos dessa corrente o nascituro tem direitos, todavia, sob condição suspensiva, qual seja, o nascimento com vida.

Em última análise, destaca-se a Teoria Natalista, corrente que prevalece na doutrina tradicional e segundo a qual a personalidade jurídica inicia-se a partir do nascimento com 
vida. Mais uma vez surge a condição nascer com vida para se adquirir a personalidade e a capacidade de ser titular de direitos.

Determinar o início da investidura do nascituro na personalidade civil passa pela escolha de qual teoria seria a mais adequada, o que o certamente influenciaria a decisão sobre o aborto de fetos anencéfalos. Nessa linha de intelecção, urge aqui uma breve anotação sobre o status jurídico do embrião durante fase inicial da gestação. Há duas posições antagônicas em relação ao ponto. De um lado, os que sustentam que existe vida desde a concepção, desde que o espermatozoide fecundou o óvulo, dando origem à multiplicação das células. De outro lado, estão os que sustentam que antes da formação do sistema nervoso central e da presença de rudimentos de consciência - o que geralmente se dá após o terceiro mês da gestação - não é possível ainda falar-se em vida em sentido pleno.

Em verdade, não há solução jurídica para esta controvérsia. Ela dependerá sempre de uma escolha religiosa ou filosófica de cada um a respeito da vida. Porém, exista ou não vida a ser protegida, o que não se questiona é a impossibilidade de o embrião subsistir fora do útero materno nesta fase de sua formação. Ou seja: ele dependerá integralmente do corpo da mãe. Esta premissa, factualmente incontestável, está subjacente às ideias que se seguem. Dentro deste contexto, emerge que a legislação brasileira não confere personalidade jurídica ao nascituro, mas põe a salvo os seus direitos desde o momento da concepção (art. $2^{\circ}$ do Código Civil).

Destaca-se que para definir o início de proteção da vida para fins de aborto é necessária uma definição jurídica adotada pela sociedade e pelo ordenamento vigente, pois as teorias doutrinárias são as mais variadas possíveis e fisiologicamente não há um conceito que permita definir, com consenso, um marco inicial para a vida.

Tecidas as premissas inaugurais, salienta-se que nas legislações penais contemporâneas há três tratativas pertinentes ao aborto, que dependerão das especificidades de cada país, e estão diretamente relacionados a fatores sociais, culturais, religiosos, morais e de políticas públicas. Há uma abordagem bastante restritiva que criminaliza o aborto, como ocorre no direito penal brasileiro. Outra mais permissiva, que consente o aborto em um número maior de casos como, por exemplo, prole numerosa, ausência de recursos, idade da mulher, etc. Por fim, há uma abordagem bastante liberal, utilizada por países como Japão, 
Suécia, Rússia, Hungria, que confia a decisão à mulher e permite que o médico decida quanto ao abordo (COSTA JR. e COSTA, 2010, p. 372).

O Direito penal brasileiro, por sua vez, adotando uma posição restritiva, considera o aborto como a interrupção do processo de gestação ocorrida entre a concepção e o início do parto, decorrente de uma conduta humana dolosa e que provoca a morte do nascituro:

"Considera-se aborto a interrupção da gravidez com a consequente destruição do
produto da concepção. Consiste na eliminação da vida intrauterina. Não faz parte do
conceito de aborto, a posterior expulsão do feto, pois pode ocorrer que o embrião
seja dissolvido e depois reabsorvido pelo organismo materno, em virtude de um
processo de autólise; ou então pode suceder que ele sofra processo de mumificação
ou maceração, de modo que continue no útero materno. A lei não faz distinção entre
o óvulo fecundado ( 3 primeiras semanas de gestação), embrião ( 3 primeiros meses),
ou feto (a partir de 3 meses), pois em qualquer fase da gravidez estará configurado o
delito de aborto, quer dizer desde o início da concepção até o início do parto"
(CAPEZ, 2008, p. 119).

A primeira espécie de aborto digna de nota ocorre quando, por motivos de ordem física, biológica, ou qualquer outra causa espontânea, o processo de gestação se torna inviável por si só, chamado de aborto espontâneo ou natural, não sendo o caso, por conseguinte, de tutela do direito penal. Na mesma direção se insere o aborto acidental, que pode ser definido como aquele decorrente de influências externas, livre de qualquer vontade e que provoca ou da causa à interrupção da gestação com a morte do nascituro.

Noutro viés, passando à seara do Direito Penal, vale nominar como a gênese dos tipos penais o aborto provocado, isto é, aquele que decorre de uma conduta, voltada direta ou indiretamente a promover a interrupção do processo gestacional, vulnerando o ser humano ali em formação e suprindo-lhe a vida. Ao direito penal é esta conduta que interessa na definição do tipo incriminador do aborto.

No Brasil, existem, pois, três tipos penais incriminadores relacionados ao aborto, cada um punindo uma conduta distinta, quais sejam: o art. 124 do Código Penal, que pune o autoaborto e o consentimento para o aborto; o aborto praticado por terceiro sem o consentimento da gestante, descrito no art. 125; e o aborto praticado por terceiro com o consentimento da gestante, tipificado no art. 126 do Código Penal.

Apesar de adotar como regra a criminalização do aborto, o legislador infraconstitucional já autoriza a prática do aborto nas hipóteses de aborto necessário e humanitário, estabelecidas no art. 128 do Código Penal. Segundo este artigo, não deve ser punido o aborto praticado pelo médico se não houver outro meio de salvar a vida da gestante 
(inciso I) ou se a gravidez resultar de estupro (inciso II), sendo apenas permitido o aborto nesta última hipótese com o consentimento da gestante (LIMA. 2012, p. 62).

Salienta-se que a lei impõe a este tipo de crime o julgamento pelo Tribunal do Júri, tal como no crime de homicídio, apensar da pena para o aborto provocado ser muito menor (de 1 a 3 anos) do que a prevista para o homicídio simples (de 6 a 20 anos). Porém, o fato de situar-se o aborto provocado voluntariamente na lei criminal, e no capítulo dos crimes contra a vida, reflete o nível de reprovação moral atribuída à conduta, mesmo que a pena concreta estabelecida seja equivalente às atribuídas aos crimes de menor potencial ofensivo (VENTURA, 2009, p. 178).

Vislumbra-se que a última lei brasileira que tratou da criminalização do aborto possui quase oitenta anos e, ao longo desse tempo, a sociedade, assim como os conflitos e as demandas sociais evoluíram e se atualizaram. Por esta razão, nota-se que há um descompasso entre a realidade social e o ordenamento jurídico, que é insuficientemente debatido ou solucionado no âmbito do Legislativo.

\section{A ATUAÇÃO dA CORTE CONSTITUCIONAL BRASILEIRA FRENTE AO SILÊNCIO LEGISLATIVO}

Diante da acelerada evolução social, política e cultural, o poder Judiciário tem ocupado um papel de destaque no cenário sociopolítico brasileiro nas últimas décadas, especialmente após o advento da Constituição de 1988, quando passou a atuar proativamente frente a temas relevantes e controversos, inclusive políticos, que são constantemente levados à apreciação do Tribunal seja porque a legislação existente para tratar do assunto é insuficiente, distante da realidade em face da época de sua criação ou em alguns casos totalmente omissa.

Assim, a fim de que as leis possam acompanhar o desenvolvimento e a velocidade dos conflitos sociais, o Supremo Tribunal Federal tem atuado, por meio de práticas interpretativas e decisórias, na defesa dos direitos constitucionalmente assegurados, sobre questões que usualmente deveriam ser solucionadas pelo poder legislativo, a quem incumbiria de fato a elaboração e modificação das leis.

Essa prática vem sendo aplicada à temática do presente trabalho, quando se aborda a questão da omissão legislativa leva-se em consideração a ausência de efetiva atuação do Legislativo na discussão sobre a matéria, bem como de tomada de conclusões a respeito do 
assunto. Nota-se que o aborto há muito tempo é considerado um relevante problema de saúde pública e que a discussão a respeito da manutenção de sua tipificação não é recente.

Há anos projetos de lei ${ }^{1}$ acerca da descriminalização do aborto são propostos pelo Legislativo, porém, em regra, não são sequer pautados para votação e quando levados à discussão não se debatem os aspectos jurídicos sobre o tema, importando mais o peso de argumentos religiosos e morais defendida por cada partido em particular, que não podem se confundir com a tecnicidade jurídica exigida pelo assunto. A tentativa de modificação da lei penal por meio de processo legislativo não tem obtido êxito. Os projetos de leis para a ampliação dos permissivos legais para o abortamento, ou aqueles que preveem a retirada do aborto do rol de crimes, ou a legalização da prática, são sistematicamente arquivados (VENTURA, 2009, p. 182).

A falta de agenda política para tratar com seriedade o assunto está intimamente relacionada à rejeição de grande parte da população sobre o tema, o que faz com que a matéria enfrente o que os cientistas políticos chamam de "ponto cego legislativo" (legislative blidspot), ou seja, temas que não são alcançados pelo debate parlamentar. Nesse sentido, discorreu o Ministro Marco Aurélio em seu voto na ADPF 347:

Legisladores e governantes temem os custos políticos decorrentes da escolha por
esse caminho, acarretando a incapacidade da democracia parlamentar e dos governos
popularmente eleitos de resolver graves problemas de direitos fundamentais. A
história possui vários exemplos de agentes políticos haverem acionado cortes
constitucionais, visando encontrar soluções a casos moralmente controvertidos e
impopulares e, assim, evitar choques com a opinião púbica. Os poderes majoritários
apostam no perfil contramajoritário das cortes constitucionais ou supremas:
condenadas judicialmente a atuar, autoridades públicas se escudam no Estado de
Direito e no consectário dever de observar ordens judiciais para implementar aquilo
que teriam feito voluntariamente se não temessem custos políticos (BRASIL, online,
2015).

Recentemente, após a movimentação do Supremo Tribunal Federal que ameaça decidir a respeito da manutenção ou descriminalização da conduta nos moldes previstos na legislação atual, o Legislativo, por meio de três comissões da Câmara e do Senado organizou um evento para debater o assunto, aduzindo que a legitimidade para decidir sobre a questão seria do próprio Congresso, casa que representa a povo, e não do Judiciário (CÂMARA NOTÍCIAS, 2018).

\footnotetext{
${ }^{1}$ PL 1.135/91; PL 3.280/92, PL 176/95; PL 1.956/96; PL 4.304/96; PL 2.929/97; PL 3.744/04; PL 4.834/05; PL 7633/14; PL 882/2015, com o PL 891/2015 apensado; todos da Câmara dos Deputados.
} 
No entanto, ainda se verifica a enorme dificuldade do Legislativo em analisar objetivamente os aspectos jurídicos acerca da ponderação de direitos fundamentais, sem incutir nos debates aspectos pessoais e convicções particulares ou mesmo dos próprios partidos ao qual pertencem os seus membros, notadamente em assuntos que envolvem um grau elevado de complexidade e ampla repercussão social.

Assim, diante da demora ou ausência de atitude legislativa do Poder legitimado, o Judiciário, ao constatar o grave problema de saúde pública e a frequente violação de direitos fundamentais, acaba por adotar postura ativa ao decidir sobre questões de cunho político, de implementação de políticas públicas ou escolhas morais em temas controversos na sociedade, ainda que em sede criminal, interpretando-as conforme a norma constitucional e os princípios democráticos. Essa atuação criativa do Supremo é denominada de ativismo judicial. Segundo conceito de Miarelli e Lima:

Por "ativismo judicial" entende-se o papel criativo dos tribunais ao fazerem uma contribuição nova para o direito, decidindo sobre a singularidade ao caso concreto, formando o precedente jurisprudencial, antecipando-se, muitas vezes, à formulação da própria lei. Diante de necessidades que forjam uma determinada interpretação, do texto de lei, é o momento em que o esforço do interprete faz-se sentir. Tem-se como ativismo judicial, portanto, a energia emanada dos tribunais no processo da criação do direito (MIARELLI e LIMA, 2012, p. 34).

O ativismo judicial é, portanto, a atitude proativa do aplicador da norma, que, ao interpretar a Constituição, expande o seu sentido e alcance. Normalmente ele se instala em situações de retração do Poder Legislativo, de um certo descolamento entre a classe política e a sociedade civil, impedindo que as demandas sociais sejam atendidas de maneira efetiva (BARROSO, 2010, p. 389).

O espaço especial do ativismo judicial é o das importantes questões constitucionais, aquelas que interferem marcadamente nos processos político-democráticos, que se ocupam de tormentosos conflitos de valores morais e políticos, principalmente envolvendo direitos fundamentais e limites de autoridade do governo, que mobilizam os poderes políticos e a sociedade em torno da solução a ser dada pela corte, como discriminação racial e de gênero; ações afirmativas; aborto; direito à morte digna; direito das minorias; direito dos homossexuais; pena de morte; políticas públicas e justiça distributiva; etc. (CAMPOS, 2014, p. 140).

As mudanças sociais ocorrem de forma muito célere, assim como o surgimento de novas questões levadas à apreciação do Judiciário. Ocorre que a legislação não caminha no 
mesmo ritmo, o próprio Código Penal de 1940 foi publicado segundo a cultura, costumes e hábitos dominantes na década de 30. Passaram-se mais de sessenta anos, e, nesse lapso, não foram apenas os valores da sociedade que se modificaram, mas principalmente os avanços científicos e tecnológicos, que produziram verdadeira revolução na ciência médica (BITENCOURT, 2017, p. 184).

Apesar das críticas relacionadas à falta de legitimidade democrática direta do Judiciário para atuar de forma expansiva, indo além da interpretação restritiva da lei em suas decisões, deve-se valorizar a vitaliciedade do cargo, uma vez que os ministros não serão punidos ou destituídos ao tomarem decisões necessárias sobre assuntos polêmicos, que desagradam parte da população, buscando proteger o direito das minorias. Sobre o papel contramajoritário da jurisdição constitucional e a sua posição de guardião dos direitos fundamentais e do Estado Democrático de Direito aduzem Brega Filho e Alves:

\footnotetext{
"Pensamos, contudo, que isso, considerando que o Supremo Tribunal Federal muitas vezes deve exercer um papel contramajoritário, ao invés de ser um defeito, seja uma virtude. Sabendo que não podem ser controlados pelo povo através do voto, os Ministros podem ter mais isenção em suas decisões (BREGA FILHO e ALVES, 2015, p. 130).
}

Não obstante, a vantagem prática do ativismo judicial e suas decisões estruturais é a possibilidade de aplicação ponderada da norma, buscando relacionar os meios disponíveis, os fins estabelecidos pelo ordenamento jurídico e os efeitos concretos da norma jurídica discutida para a proteção da pessoa, ora de forma imediata, ora por meio de comandos escalonados de implementação. O resultado desse processo interpretativo judicial pode ser replicado e constituir-se, após reiteradas decisões, em jurisprudência, que servirá como normativa válida no sistema jurídico vigente, sem que necessariamente se produza uma lei específica ou expressa. Nesse sentido, nota-se o caráter preventivo de tal mecanismo, que serve, outrossim, para prevenir ou mesmo evitar a perpetuação de uma determinada violação de direitos, por ausência ou morosidade na reforma das leis (VENTURA, 2009, p. 184).

Sobreleva destacar que apesar da importância do ativismo judicial na proteção dos direitos fundamentais, ele não pode ser exercido de forma indiscriminada, devendo sempre ser aplicado com base na racionalidade jurídica vigente, com uma análise minuciosa dos impactos das decisões para a sociedade e com auxílio técnico quando relacionadas a questões específicas que fogem ao conhecimento dos magistrados. Qualquer decisão ativista que se afastar dos objetivos de garantia dos direitos fundamentais e da supremacia da Constituição poderá ser considerada nociva, sobretudo se fazer preponderar um padrão de racionalidade 
eminentemente político (TEIXEIRA, 2012, p. 46). O próprio texto constitucional limita objetivamente a interpretação do Judiciário, não podendo chegar a um ponto em que se reescreva o seu conteúdo (RAMOS, 2010, p. 131).

Ademais, os princípios constitucionais, positivados expressa e implicitamente, estão amalgamados com a base externa que podem justificar ou não as leis criminalizadora, limitando ou não o seu conteúdo. Suas irradiações importam numa demarcação racional das possibilidades do legislador e do juiz, circunscrevendo a discricionariedade e a interpretação legislativa e judiciária, funcionando como verdadeiro parâmetro argumentativo para o controle da atividade destes atores (LIMA, 2012, p. 38).

Em suma, para garantir a legitimidade de suas decisões, o Judiciário ao fazer uso do ativismo judicial, deve motivar as suas decisões com argumentos racionais e persuasivos, a partir de um exame criterioso dos casos concretos, respeitando os limites dos princípios e regras constitucionais e utilizando-se da proporcionalidade e da ponderação sempre que houver colisão entre princípios.

\section{AS DECISÕES DO STF E A PROTEÇÃO AOS DIREITOS FUNDAMENTAIS DA MULHER}

Conforme apresentado no capítulo anterior, a evolução social e cultural de um povo faz com que os valores defendidos pela sociedade sejam constantemente modificados. Nessa perspectiva, verifica-se que a mulher, ainda considerada como uma minoria, passou por um histórico de sofrimento e discriminação, marcado por um ranço cultural de supremacia do gênero masculino, sendo que seus direitos e sua vontade passaram a ser considerados há poucas décadas, quando finalmente as democracias liberais adotaram progressivamente a antidiscriminação com o objetivo de assegurar a igualdade de direitos entre homens e mulheres.

Nesse diapasão, ainda se luta pela igualdade de gênero, que envolve entre outros direitos a liberdade sobre o próprio corpo, a liberdade sexual e a liberdade de escolha. $\mathrm{O}$ Supremo Tribunal Federal tem atuado na defesa desses direitos e na tentativa de minimizar a distância entre os sexos, reconhecendo que em determinados casos a vida intrauterina pode ser objeto de ponderação quando enfrenta direitos de outra natureza relativos à integridade moral e física das mulheres. 
Partindo desta premissa, o Supremo Tribunal Federal vem se valendo do ativismo judicial para superar a barreira temporal das leis, especialmente no que se refere à definição de crimes e penas, buscando interpretá-las de acordo com as necessidades atuais:

\begin{abstract}
Cabe acrescentar, ainda, que o Código Penal brasileiro data de 1940. E, a despeito de inúmeras atualizações ao longo dos anos, em relação aos crimes aqui versados arts. 124 a 128 - ele conserva a mesma redação. Prova da defasagem da legislação em relação aos valores contemporâneos foi a decisão do Supremo Tribunal Federal na $\mathrm{ADPF} \mathrm{n}^{\circ}$ 54, descriminalizando a interrupção da gestação na hipótese de fetos anencefálicos. Também a questão do aborto até o terceiro mês de gravidez precisa ser revista à luz dos novos valores constitucionais trazidos pela Constituição de 1988, das transformações dos costumes e de uma perspectiva mais cosmopolita (BRASIL, online, 2012).
\end{abstract}

Cumpre, pois, realizar uma análise atenta dos principais argumentos utilizados pela Suprema Corte em julgamentos recentes e emblemáticos que resguardam os direitos fundamentais das mulheres ao analisar os dispositivos legais que tratam do aborto e os desdobramentos práticos oriundos desses novos entendimentos.

\title{
3.1 A DESCRIMINALIZAÇÃO DO ABORTO DO FETO ANENCÉFALO
}

O Conselho Federal de Medicina, por meio da Resolução 1.752/2004, considerou que os anencéfalos são natimortos cerebrais, pois não possuem os hemisférios cerebrais compatíveis com a vida extrauterina, o que impede o surgimento do ser humano em perspectiva. A própria Resolução traz a possibilidade da antecipação terapêutica do parto e trata a opção de manutenção da gravidez como uma atitude dos pais merecedora do mais elevado sentimento de solidariedade.

Ocorre que, destoando da referida Resolução, o Código Penal brasileiro apenas autoriza a realização do aborto nas situações previstas expressamente em lei, o que excluiria o aborto do feto anencéfalo ainda que, com um diagnóstico preciso, inexista qualquer viabilidade de vida após o parto. Diante disso, o debate sobre a possibilidade de escolha para antecipar o parto nos casos específicos de diagnóstico de feto anencéfalo foi levado à esfera jurídica, pois os danos físicos e psicológicos ocasionados à mulher obrigada a manter uma gestação onde não haverá possibilidade de vida após o parto são incalculáveis.

Com efeito, a constitucionalização do direito e das relações sociais leva a jurisdição de natureza constitucional a tratar questões das mais controvertidas, notadamente aquelas que colocam em choque direitos de magnitude constitucional. A complexidade de casos propostos perante o Supremo Tribunal Federal, como o caso do aborto terapêutico de feto anencéfalo, personificam a missão constitucional da Corte Constitucional não somente com os olhos 
voltados para os direitos fundamentais e à dignidade da pessoa humana, mas também em busca da decisão que melhor conforme a situação fática ao texto constitucional e à evolução de sua interpretação (MINGATI, GÓES e COSTA, 2012, p. 7).

O plenário do STF, em 2012, analisando conjunturalmente todas as particularidades destes casos, julgou procedente a ADPF 54 permitindo a realização do aborto de feto anencefálico em face da inviabilidade de vida extrauterina, preservando-se a liberdade de escolha e a própria dignidade da mulher que deseja interromper a gravidez nesta situação:

\begin{abstract}
Some-se a isso o fato de o meio adequado e necessário para a proteção da vida do feto - a postura interventiva do Estado - ferir, além da liberdade, a integridade física e psicológica da mulher, seja na esfera da saúde (os riscos são maiores na gestação e o abalo psicológico é drástico e inegável), seja na esfera da dignidade humana, pois, se há dúvida sobre a viabilidade de vida para o feto anencéfalo, a imposição da gestação contra a vontade da mulher é tortura física e psicológica em razão de crença (não importa se institucionalizada por meio de lei ou de decisão jurídica, ainda é mera crença), nos exatos termos da Lei dos Crimes de Tortura (BRASIL, online, 2012).
\end{abstract}

No voto-vista proferido em sede de liminar, o Ministro Ayres Brito deixou claro que a conduta não poderia ser punida em face da atipicidade da própria conduta, pois "o crime deixa de existir se o deliberado desfazimento da gestação não é impeditivo da transformação de algo em alguém" e se a figura típica existe para proteger a vida de um ser humano em potencial, faltando essa potencialidade vital, aquela vedação penal já não tem como permanecer (BRASIL, online, 2004).

Destaca-se que a ADPF é o meio possível de se discutir acerca da recepção constitucional de uma norma anterior à Constituição Federal de 1988, a fim de evitar ou reparar lesão à preceitos fundamentais, in casu, a manutenção da criminalização pelo Código Penal, datado de 1940, do aborto do feto anencefálico violaria os princípios da dignidade da pessoa humana, da legalidade, em seu conceito maior, da liberdade e autonomia da vontade, bem como os relacionados com a saúde (BRASIL, online, 2012).

Nesta oportunidade, não se buscou postular a proclamação da inconstitucionalidade abstrata dos tipos penais referentes ao aborto e debater-se acerca da descriminalização do aborto, mas tão somente que os referidos enunciados fossem interpretados de acordo com a Constituição no caso específico relacionado à ausência de expectativa de vida para o feto. Nas palavras do Min. Joaquim Barbosa "a questão se refere exclusivamente à interrupção de uma gravidez que está fadada ao fracasso, pois seu resultado, ainda que venham a ser envidados todos os esforços possível, será, invariavelmente, a morte do feto" (BRASIL, 2012). 
Inclusive, o próprio acórdão assinala a diferença entre as figuras do aborto e da antecipação terapêutica do parto, pontuando que a pretensão, caso constatada a anencefalia do feto, seria de obter autorização para a realização desta.

Assim, utilizando-se do comparativo com as demais hipóteses que excluem a ilicitude da prática do aborto, entendeu-se que seria um contrassenso chancelar a liberdade e a autonomia privada da mulher, como ocorre nos casos de aborto sentimental, onde a vida extrauterina seria plenamente viável, e vedar o direito a essa liberdade nos casos de malformação fetal gravíssima, como a anencefalia, onde não há viabilidade de vida extrauterina (BRASIL, online, 2012).

Destaca-se que de forma alguma a decisão visa tornar obrigatória a antecipação do parto em qualquer hipótese, mas apenas possibilitar que a mulher exerça o seu direito de escolha de acordo com suas convicções morais, éticas e religiosas, podendo decidir livremente se deseja manter a gravidez, mesmo diante da inviabilidade de vida do feto, ou se deseja levá-la a termo.

Destarte, revela-se imprescindível o papel dos instrumentos e técnicas de interpretação constitucional, em particular, da interpretação conforme a Constituição. Instrumental este que, no caso sob análise, permite a preservação da dignidade da pessoa humana, materializada não apenas na figura individual da mulher, mas na figura da gestante, da mãe, que vive, protege e sofre com a sua dignidade e com a dignidade do feto (MINGATI, GOÉS e COSTA, 2012, p. 8).

A partir desta emblemática decisão, com eficácia erga omnes e efeito vinculante, foi declarada a inconstitucionalidade de qualquer interpretação que impeça a mulher, por escolha própria, de realizar voluntariamente a antecipação terapêutica do feto anencefálico, retirando do Estado o poder de decisão nestes casos específicos.

\subsection{A DESCRIMINALIZAÇÃO DO ABORTO NO PRIMEIRO TRIMESTRE DA GESTAÇÃO}

Em novembro de 2016, a $1^{\text {a }}$ turma do STF julgou, a partir do voto do presidente, ministro Luís Roberto Barroso, que a criminalização do aborto no primeiro trimestre da gestação viola diversos direitos fundamentais das mulheres - como a autonomia, a integridade física e psíquica, a igualdade de gênero e os direitos sexuais e reprodutivos - , bem como o princípio da proporcionalidade. 
A decisão é oriunda de Habeas Corpus no 124.306 impetrado no estado do Rio de Janeiro em favor de dois acusados que foram presos preventivamente pela prática de aborto em clínica clandestina e que foram denunciados juntamente com a gestante que consentiu com o aborto. Durante o julgamento, o Ministro Marco Aurélio além de votar pela admissão do habeas corpus e afastamento da custódia provisória, foi além e adentrou no mérito da criminalização do aborto expondo o seu posicionamento acerca da inconstitucionalidade do dispositivo penal.

Com base nessa decisão, realizada em sede de controle concentrado de constitucionalidade, o colegiado entendeu que são inconstitucionais os artigos 124 e 126 do Código Penal, que punem tanto o aborto provocado pela gestante, quanto por terceiros com o consentimento da gestante. Destaca-se que a decisão não apresentou condição específica para a prática do aborto, como faz o artigo 128 do Código Penal, mas ressaltou a importância de se discutir a respeito da constitucionalidade do crime que pune a interrupção voluntária da gestação, quando efetivada no primeiro trimestre. Por certo que a discussão sobre a descriminalização alude apenas as práticas consentidas, uma vez que a ausência do consentimento da mãe para o aborto implica em uma violação ainda maior do direito à vida $\mathrm{e}$ do direito de escolha.

Partindo-se para a análise jurídica da questão, o primeiro argumento que embasa a decisão que a manutenção da criminalização do aborto viola diversos direitos fundamentais da mulher, entre eles, a autonomia, a integridade física e psíquica, os direitos sexuais e reprodutivos, a igualdade de gênero e a igualdade social (BRASIL, online, 2015).

Sobre a autonomia e liberdade individual da mulher, entende-se que ela deve ser livre para fazer a sua escolha e decidir sobre o próprio corpo, sem que isso implique em uma pena de prisão. O Estado, ao obrigar que a mulher, mesmo contra a sua vontade, mantenha uma gravidez indesejada até o final da gestação gera efeitos diretos relacionados à sua integridade física e principalmente psíquica.

Segundo Bobbio (1909, p. 8), a democraticidade de um regime é auferida de acordo com a maior ou menor liberdade de que desfrutam os cidadãos e pela igualdade existente entre eles, portanto, em um governo que se denomina democrático, proteger a vontade da mulher significa proteger a própria liberdade, classificada por Bobbio (1909, p. 51-52) como positiva na linguagem política, onde o sujeito pode tomar decisões sem ser determinado pelo 
querer de outros, mais especificamente neste caso o querer do Estado, possuindo autodeterminação e autonomia para realizar suas escolhas.

É consensual o entendimento de que a vida e dignidade humana constituem o principal bem jurídico a ser protegido. A vida digna passa a ser legitimada como o beminteresse de maior valor nos estatutos éticos e legais de direitos humanos, consolidados a partir da Modernidade. Contudo, constata-se que no momento de deliberar-se sobre o direito ou não da mulher ao aborto voluntário há, claramente, uma centralidade da discussão do aborto em torno do direito à vida do feto, que é contraposto, na maioria das vezes de forma simplista, ao direito de liberdade de escolha da mulher (VENTURA, 2009, p. 178).

Com relação à violação ao direito à integridade física e psíquica da mulher, cumpre salientar que a gravidez é um processo fisiológico que gera inúmeras transformações no corpo da mulher, sejam de ordem física, como de ordem psicológica, o que, naturalmente já despende de compreensão e resiliência da mulher para tentar lidar com todos os riscos e as mudanças do período, que implicarão em renúncias, dedicação e comprometimento.

Porém, estas transformações podem se tornar um verdadeiro fardo para a mulher, caso a gravidez não seja desejada e ela se veja obrigada a prosseguir com a gestação, abalando a sua integridade física e psíquica. Nos dizeres do Ministro Marco Aurélio, "o que seria uma benção se decorresse da vontade própria, pode se transformar em provação quando decorra de uma imposição heterônoma. Ter um filho por determinação do direito penal constitui grave violação à integridade física e psíquica de uma mulher” (BRASIL, online, 2015).

Nesse trilhar, verifica-se que a criminalização do aborto viola ainda os direitos sexuais e reprodutivos da mulher. Sabe-se que culturalmente a mulher durante muitos anos foi tratada como uma propriedade do homem, devendo servir aos seus desígnios, inclusive na esfera sexual. O reconhecimento dos direitos sexuais e reprodutivos das mulheres evoluiu muito nas últimas décadas, mas ainda sofre limitações, notadamente na esfera legal.

Sobreleva destacar que, segundo a definição de direitos reprodutivos elaborada na Conferência de Cairo (Conferência Internacional sobre População e Desenvolvimento das Nações Unidas - CIPD, 1994), "a saúde reprodutiva inclui a capacidade de desfrutar de uma 
vida sexual satisfatória e sem riscos de procriar, e a liberdade para decidir fazê-lo ou não, quando e com que frequência" conforme consta do Capítulo VII do Relatório².

Ademais, o tratamento do aborto como crime viola a igualdade de gênero e sedimenta o machismo ainda presente na sociedade brasileira, citando as palavras do próprio Ministro Ayres Brito: "Se os homens engravidassem, não tenho dúvida em dizer que seguramente o aborto seria descriminalizado de ponta a ponta" (BRASIL, online, 2004).

Outra causa que justificou a decisão recente do Supremo diz respeito à desigualdade material incutida pelo crime de aborto. A criminalização do aborto atinge fundamentalmente as mulheres pobres, segundo pesquisa realizada pelo Ministério da Saúde (BRASIL, online, 2009), uma vez que aquelas com recursos fazem abortos em clínicas e médicos particulares que, apesar de ilegais, em regra, fornecem o mínimo de segurança nos procedimentos, com acompanhamento de médicos, mantendo a discrição e o sigilo com relação ao fato e à mulher.

Às mulheres pobres, por sua vez, restam os abortos inseguros, geralmente autoabortos, realizados em casa, com a ingestão de medicamentos, chás, ou o uso de instrumentos perfurantes, que podem causar danos irreversíveis à saúde, levando a esterilização ou até mesmo à morte. Justamente nesses casos, quando não restam mais opções e a mulher continua sofrendo as consequências do aborto mal realizado, é obrigada a se socorrer da saúde pública e então acaba sendo denunciada pelo ato criminoso. Nesse sentido, foi o voto do Ministro Barroso:

[...] a tipificação penal produz também discriminação social, já que prejudica, de forma desproporcional, as mulheres pobres, que não têm acesso a médicos e clínicas particulares, nem podem se valer do sistema público de saúde para realizar o procedimento abortivo. Por meio da criminalização, o Estado retira da mulher a possibilidade de submissão a um procedimento médico seguro. Não raro, mulheres pobres precisam recorrer a clínicas clandestinas sem qualquer infraestrutura médica ou a procedimentos precários e primitivos, que lhes oferecem elevados riscos de lesões, mutilações e óbito. (BRASIL, online, 2012)

É evidente, portanto, a discriminação social e impacto desproporcional sobre mulheres pobres causados pela tipificação do aborto, uma vez que estas têm sido as mais prejudicadas pela criminalização da conduta nos moldes atuais. Desta feita, a manutenção do

\footnotetext{
${ }^{2} \S$ 7.3. Esses direitos se baseiam no reconhecido direito básico de todo casal e de todo indivíduo de decidir livre e responsavelmente sobre o número, o espaçamento e a oportunidade de seus filhos e de ter a informação e os meios de assim o fazer, e o direito de gozar do mais alto padrão de saúde sexual e de reprodução. Inclui também seu direito e tomar decisões sobre a reprodução, livre de discriminação, coerção ou violência, conforme expresso em documentos sobre direitos humanos.
} 
crime nos termos do Código Penal de 1940 coaduna com a seletividade do tipo penal, que viola diretamente o princípio constitucional da isonomia.

Além da violação aos direitos fundamentais da mulher, baseando-se no princípio da proporcionalidade e nos subprincípios que o compõem, entende-se que o tipo penal só se justifica se protege a sociedade de maneira suficiente e sem valer-se do excesso. Portanto, o tipo penal deverá ser adequado, necessário e proporcional em sentido estrito, sopesando-se os seus custos e benefícios (BRASIL, online, 2012).

Sobre a adequação, discorre o Ministro Luís Roberto Barroso em seu voto que a criminalização da conduta não resguarda a vida do feto e não impede as mulheres de praticarem o aborto, constituindo apenas uma reprovação simbólica, portanto, não seria a via adequada de intervenção do Estado que deveria estar mais engajado em melhorar aspectos da saúde pública e fornecer o devido suporte à mulher para que esta faça uma escolha consciente (BRASIL, online, 2012).

No mesmo sentido, ao analisar a necessidade do tipo penal, verifica-se que o direito penal deve ser utilizado como ultima ratio no exercício impositivo da força, portanto, existem outras formas mais eficazes de redução efetiva da prática do aborto, consistes na atuação do Estado e investimento em políticas públicas que atendam às mulheres, dando-lhes alternativas e suporte, tanto psicológico com assistencial, notadamente na fase gestacional, mas também após o nascimento da criança.

Importante lembrar que o aborto não deixa de ser um problema de saúde pública, cuja responsabilidade incumbe ao Estado. A conscientização, prevenção, controle da gravidez e amparo à gestante devem ser objetivos primordiais do Estado no combate à prática de abortos. Os principais motivos que levam à realização do aborto são a falta de condições financeiras para arcar com os custos de vida de um filho e a desestabilidade emocional, sendo que ambos possuem solução que pode ser provida pelo Estado.

É conveniente para o Estado responsabilizar a mulher pela morte do feto, quando ele próprio não possui condições de atendê-las de forma humanizada sequer no momento do parto, tornando-se, por descaso, falta de atendimento e condições adequadas na saúde pública, o responsável por milhares de mortes de fetos e crianças. Destaca-se que o Sistema Único de Saúde não proporciona a mulher sequer o direito de escolha sobre a forma do parto, impondo um parto normal, salvo em circunstâncias extremas que o impeçam de acontecer. 
Carlos Alberto Bittar ao discorrer sobre os direitos da personalidade relativos ao nascituro defende que o caminho mais seguro para conduzir a questão relativa à escolha dos pais pelo aborto deve se dar pela assistência, acolhimento e tratamento pelo Estado, a fim de disponibilizar formas de programação familiar e orientação terapêutica, que demonstrará as consequências e responsabilidades pela escolha:

A multiplicação de clínicas clandestinas, a ruptura do código de ética em caso de aceitação de procedimentos dessa natureza pelo médico, a forma como se trata o descarte do aborto, os riscos para a vida da gestante em casos de má qualidade do serviços médico executado, o uso de técnicas altamente perfurantes e o uso de medicamentos de má qualidade apontam para o caminho da descriminalização, e para a indução de políticas públicas de orientação, acolhimento, assistência social e psicológica, bem como de legalização dos procedimentos de aborto pelo sistema público de saúde. A repressão penal, portanto, mostrou-se ineficaz em processar o desestímulo da conduta (BITTAR, 2015, p. 125).

Depreende-se, pois, que o Estado não deve socorrer-se do Direito Penal para a solução dos problemas sociais, transferindo ao plano simbólico o que deveria resolver com ações políticas, administrativas e econômicas, especialmente no âmbito das ações governamentais de políticas públicas. Não se pode admitir uma política criminal simbólica que não propicie a efetiva aplicação da lei, resignada com punições restritas a determinados fatos cometidos por conhecidos estratos da população (LIMA, 2012, p. 35).

Insta ressaltar que o voto do Ministro abrangeu somente a descriminalização no primeiro trimestre da gravidez, período em que o córtex cerebral - que permite que o feto desenvolva racionalidade, sentimento ou pensamento - ainda não foi formado, nem há qualquer potencialidade de vida fora do útero materno. (SARMENTO, 2005, p. 65). Portanto, o respeito à vida intrauterina não deixa de existir, mas a intensidade da proteção cresce proporcionalmente ao desenvolvimento da vida humana:

\begin{abstract}
A tese que aqui se defenderá é a de que a vida humana intrauterina também é protegida pela Constituição, mas com intensidade substancialmente menor do que a vida de alguém já nascido. Sustentar-se-á, por outro lado, que a proteção conferida à vida do nascituro não é uniforme durante toda a gestação. Pelo contrário, esta tutela vai aumentando progressivamente na medida em que o embrião se desenvolve, tornando-se um feto e depois adquirindo viabilidade extrauterina. O tempo de gestação é, portanto, um fator de extrema relevância na mensuração do nível de proteção constitucional atribuído à vida pré-natal (SARMENTO, 2005, p.65).
\end{abstract}

Por tudo quanto o exposto, o Ministro Luís Roberto Barroso conclui seu voto declarando que o tipo penal do aborto nos moldes previstos pelo Código Penal de 1940 não está de acordo com as diretrizes e direitos fundamentais assegurados na Constituição Federal de 1988, razão pela qual não foi recepcionado. 
Por fim, oportuno esclarecer que não houve a descriminalização do aborto no primeiro trimestre da gravidez, pois apesar da análise aprofundada e dos fundamentos apresentados no voto, o julgamento limitava-se à discussão da manutenção da prisão preventiva em Habeas Corpus, instrumento que não permite ao STF a análise cognitiva da inconstitucionalidade ou não receptividade do tipo penal.

Para que alterar a intepretação quanto ao crime de aborto, atribuindo-lhe eficácia erga omnes e efeito vinculante, seria necessária a proposição de uma Arguição de Descumprimento de Preceito Fundamental (ADPF), como ocorreu na discussão sobre o aborto de feto anencéfalo. De todo modo, o voto despertou o debate e a atenção pública, trazendo novamente à tona a discussão sobre descriminalização do aborto, além de demonstrar que existe uma tendência da Suprema Corte nas decisões futuras sobre a questão.

\section{CONSIDERAÇÕES FINAIS}

Em que pese a evolução no pensamento social com relação aos direitos das mulheres nas últimas décadas, denota-se que a liberdade de escolha, em especial a reprodutiva e sexual ainda é limitada pelo próprio Estado em razão da legislação penal existente. Apesar disso, o Legislativo permanece inerte com relação a temas polêmicos, que geram controvérsias políticas e que naturalmente irão desagradar uma parcela da população ao serem enfrentados.

O presente trabalho buscou ampliar a compreensão das principais questões que envolvem o assunto, principalmente na esfera jurídica, onde a ponderação de direito irá implicar necessariamente na limitação de um direito fundamental para que outro seja assegurado.

A discussão, usualmente encabeçada por leigos, a respeito da descriminalização da conduta vai muito além de ser contra ou a favor da vida ou simplesmente fundada em passagens bíblicas e preceitos religiosos. Trata-se de um debate jurídico, com argumentos e assuntos relacionados a disposições legais e princípios fundamentais, devendo, portanto, permanecer nesta seara, a fim de que não perca a razão de ser.

As mencionadas decisões, entre diversas outras que repercutem o crescimento da atuação proativa do Judiciário, traduzem a necessidade de sua pronta intervenção assegurar a efetivação dos direitos fundamentais constitucionalmente previstos frente ao silêncio legislativo. A inércia do poder competente para adequar a norma à realidade social causa prejuízos diários como danos graves à saúde das mulheres, tanto mental quanto física, além de 
ressaltar a desigualdade de condições referentes à classe econômica e limitar a liberdade de escolha.

Apesar de não descriminalizar o aborto, o Supremo Tribunal Federal tem caminhado para a conclusão de que sancionar penalmente a conduta não resolve o problema, nem diminuí a sua prática. De todo modo, as decisões refletem a necessidade de mudança, bem como fomentam o debate produtivo na sociedade. Destaca-se que o reconhecer o direito ao aborto não é o mesmo que retirar a proteção da vida intrauterina, mas simplesmente reconhecer que o método atual não é eficaz e que o Estado deve buscar instrumentos mais apropriados para evitar a sua ocorrência.

\section{REFERÊNCIAS}

BARROSO, Luís Roberto. Judicialização, ativismo judicial e legitimidade democrática. Revista EMARF: Seminário Nacional sobre Justiça Constitucional, dez. 2010.

BITENCOURT, Cezar Roberto. Tratado de direito penal, 17 ed. São Paulo: Saraiva, 2017.

BITTAR, Carlos Alberto. Os direitos da personalidade. $8^{\text {a }}$ ed. São Paulo: Saraiva, 2015.

BOBBIO, Norberto. Igualdade e Liberdade. Tradução de Carlos Nelson Coutinho - $4^{\mathrm{a}}$ ed. Rio de Janeiro: Ediouro, 2000.

BRASIL. Agência Câmara Notícias. Direito e Justiça. Reportagem de 30 de maio de 2018. Reportagem: Márcia Torres. Edição: Geórgia Moraes Disponível em:

$<$ http://www2.camara.leg.br/camaranoticias/noticias/direito-e-justica/558161-seminariodebate-hoje-descriminalizacao-do-aborto.html>. Acesso em 28 fev. 2019.

BRASIL. Ministério da Saúde. 20 anos de pesquisas sobre aborto no Brasil. Ministério da Saúde, Secretaria de Ciência, Tecnologia e Insumos Estratégicos, Departamento de Ciência e Tecnologia. - Brasília: Ministério da Saúde, 2009.

BRASIL, Supremo Tribunal Federal. Arguição De Descumprimento De Preceito

Fundamental 54. Questão de Ordem. Voto Vista: Ministro Ayres Brito, 20 de outubro de 2004. Disponível em < http://www.stf.jus.br/noticias/imprensa/VotoBrittoADPF54.pdf>. Acesso em 28 fev. 2019.

BRASIL, Supremo Tribunal Federal. Arguição De Descumprimento De Preceito Fundamental 54. Relator: Ministro Marco Autélio, 12 de abril de 2012. Disponível em < http://redir.stf.jus.br/paginadorpub/paginador.jsp?docTP=TP\&docID=3707334>. Acesso em 28 fev. 2019.

BRASIL. Supremo Tribunal Federal. Medida cautelar na Arguição de Descumprimento de Preceito Fundamental 347. Relator: Ministro Marco Aurélio. Brasília, 9 de setembro de 2015. Disponível em

$<$ http://redir.stf.jus.br/paginadorpub/paginador.jsp?doctp=tp\&docid=10300665>. Acesso em 28 fev. 2019. 
BREGA FILHO, V.; ALVES, F.B. Termidorizar a Deliberação: O Papel das Cortes Constitucionais nas Democracias Contemporâneas. Revista Brasileira de Direito, v. 11, p. 124-134, 2015. Disponível em: <https://dialnet.unirioja.es/descarga/articulo/5179375.pdf>.

CAMPOS, Carlos Alexandre de Azevedo. Dimensões do ativismo judicial do STF. Rio de Janeiro: Forense, 2014.

CAPEZ, Fernando. Direito penal: parte especial. 16a .ed. São Paulo: Saraiva, 2018.

JR., COSTA, Paulo da, COSTA, Fernando José. Curso de Direito Penal, $12^{a}$ edição. São Paulo: Saraiva, 2010.

LIMA, Alberto Jorge C. Barros. Direito Penal Constitucional: A imposição dos princípios constitucionais penais. $1^{a}$ ed. São Paulo: Saraiva, 2012.

LIMA, Carolina Alves Souza. Aborto e anencefalia: direitos fundamentais em colisão. 3 . Ed. Curitiba: Juruá, 2012.

MIARELLI, Mayra Marinho; LIMA. Rogério Montai de. Ativismo Judicial e a efetivação de direitos no Supremo Tribunal Federal. Porto Alegre: Sergio Antonio Fabris, 2012.

MINGATI, Vinícius Secafen; GÓES, Winnicius Pereira de; COSTA, Ilton Garcia da. O aborto do feto anencefálico e a questão constitucional. Revista Brasileira Crescimento e Desenvolvimento Humano, vol.22. no.2. São Paulo, 2012. Disponível em: < http://www.revistas.usp.br/jhgd/article/view/44942>. Acesso em 27 fev. 2019.

MORAES, Alexandre de. Direito Constitucional, $28^{a}$ ed. São Paulo: Atlas, 2012.

RAMOS, Elival da Silva. Ativismo judicial: parâmetros dogmáticos. São Paulo: Saraiva, 2010.

SARMENTO, Daniel. Legalização do Aborto e Constituição. In: Revista de Direito Administrativo. Rio de janeiro, n.240, p.43-82, Abr/Jun. 2005. Disponível em: < http://dx.doi.org/10.12660/rda.v240.2005.43619>. Acesso: 17/08/2018.

TEIXEIRA, Anderson Vichinkeski. Ativismo judicial: nos limites entre racionalidade jurídica e decisão política. Rev. Direito GV. v. 8 n 1 São Paulo, 2012.

VENTURA, Miriam. A questão do aborto e seus aspectos jurídicos. In Aborto no Brasil e países do Cone Sul: panorama da situação e dos estudos acadêmicos. Maria Isabel Baltar da Rocha (Org.); Regina Maria Barbosa (Org.). Campinas: Núcleo de Estudos de População Unicamp, 2009. 